\title{
The loess microstructure kinds and its seismic subsidence
}

\author{
Lanmin Wang ${ }^{1}$, Jin Deng $^{1,2,3^{*}}$ \\ ${ }^{1}$ Lanzhou Institute of Seismology, CEA, Lanzhou, China; ${ }^{*}$ Corresponding Author: dengjin@gssb.gov.cn \\ ${ }^{2}$ Earthquake Administration of Gansu Province (Key Laboratory of Loess Earthquake Engineering, CEA), Lanzhou, China \\ ${ }^{3}$ Geotechnical Disaster Prevention Engineering Technology Research Center of Gansu Province, Lanzhou, China
}

Received 27 August 2012; revised 20 February 2013; accepted 28 February 2013

Copyright (C) 2013 Lanmin Wang, Jin Deng. This is an open access article distributed under the Creative Commons Attribution License, which permits unrestricted use, distribution, and reproduction in any medium, provided the original work is properly cited.

\begin{abstract}
The paper put forward a new method of loess microstructure analysis to determine whether the loess seismic subsidence deformation to be strong or weak. In the dryer and colder climatic conditions of northwest of China, the loess microstructure formed in certain conditions changed by the special climate and desert surroundings. According to its chemical element ratio (such as $\mathrm{Si} / \mathrm{Al}, \mathrm{Ca} / \mathrm{Fe}, \mathrm{K} / \mathrm{Al}, \mathrm{Ca} / \mathrm{Mg}$ ) and seismic subsidence, we could divide them into four kinds of microstructures: strong shear deformation microstructure(I); strong compaction deformation microstructure(II); the medium seismic subsidence microstructure(III); the low seismic subsidence microstructure(IV). It could generally judge and set deeply defense measures to seismic engineering.
\end{abstract}

Keywords: Loess; Microstructure; Seismic Subsidence Chemical Element Ratio

\section{INTRODUCTION}

In history geological periods of western China, there have been several times of fastest and slowest dustdropping period in loess formation [1,2]. Because of being formed under different climatic conditions, there has been special loess microstructures in certain degree deformation [3]. The existing experimental studies have shown that the original porosity loess microstructure characteristics determine its skeleton structural strength and particle cementation strength [4]. As more complex changes of dynamic indicators, such as seismic subsidence, the loess non-linear loading curve that manifested belongs to the relationship of climate forming microstructure and mechanical properties [5].
Micro-structural characteristics have a profound influence to its engineering properties of loess, and related literature [6-8]. It can be found through the microstructure of seismic damage analysis, for its region causes could provide theoretical basis to alleviate its earthquake damage. This article attempts to establish the method for microstructure indicators to analyze loess geological disasters.

\section{LOESS MICROSTRUCTURE TYPES}

Loess of different formation climate condition, for example, sand source distance, temperature, rainfall intensity, can produce different kinds of microstructure. Because loess microstructure characteristic directly impact on its loess loading deformation stability, the following list as several typical microstructure types.

\subsection{Strong Shear Deformation Microstructure(I)}

Lanzhou and Ningxia loess samples microstructure are shown in Figures 1 and 2, respectively. There is almost no cementation between particles. This microstructure primarily is near from desert, the source of sand. Respond to such a rigorous loess forming conditions and need

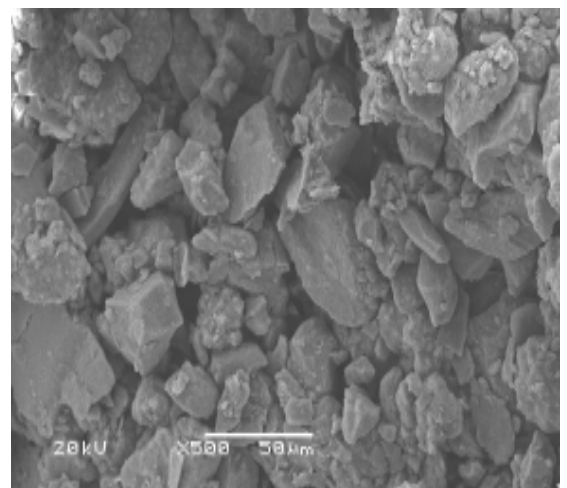

Figure 1. Lanzhou loess, $5 \mathrm{~m}$. 


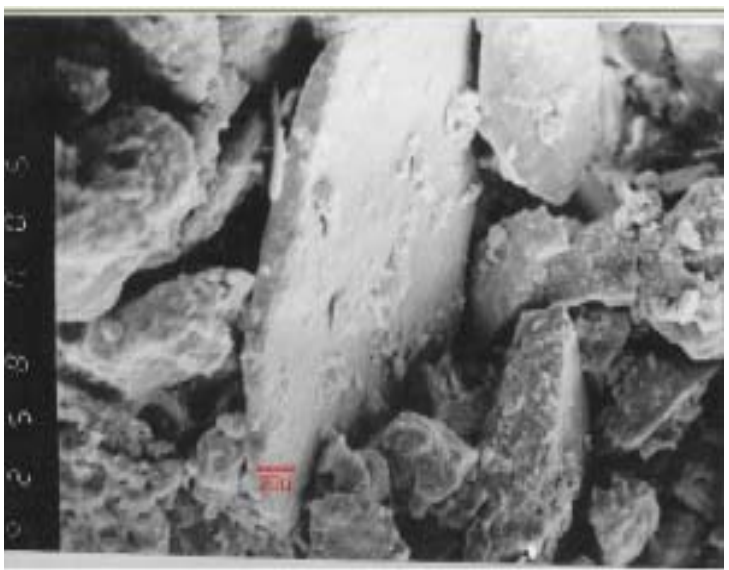

Figure 2. Ningxia landslide loess, $4 \mathrm{~m}$.

corresponding ground-based protection. It has strong shear and strain or compressive strain in deformation loading.

As Figure 2 the landslide of Xi Ji loess samples of 4 $\mathrm{m}$ deep, it has week cementation between the particles, and almost no cementing force. Its seismic subsidence coefficient is $4 \%-5.1 \%$. The large particles (Sand particles, about $80-100 \mu \mathrm{m}$ ) could produce large shear deformation, induced to landslip and or loading sliding. Its particles are accumulated in loose and have strong shear deformation features. So it has serious liquefaction, wet subsidence incline, and landslide disasters potentials. The loess there has a great disasters typical characteristic for serious shear deformation, and could induce to landslide.

\subsection{Strong Compaction Deformation Microstructure(II)}

The strong compaction deformation microstructures (II) are shown in Figures 3 and 4, respectively, as Yongdeng and Dingxi samples of Gansu province. The kinds of microstructure shows abundant elevated pores between particles. There has more strongly compaction deformation, its loess particles belong to powder grains range $(35-85 \mu \mathrm{m})$. Its seismic subsidence is also serious, but has strong collapsibility. It could take no effective approach to prevent the occurrence of earthquake damage.

II types of Yongdeng loess has plentiful overhead space pores, therefore has very strong seismic subsidence [5]. Its strong seismic subsidence coefficients most reach to $6 \%-8 \%$. After the earthquake shaking, it would generate large acceleration response peak when affected by the even a medium earthquake damage in the region. For example, Figure 3 is loess samples pictures from 1995 years, the 5.8 magnitude earthquake loess site of Yongdeng, China, the earthquake produced strong surface shear deformation and landslides in the loess regions.

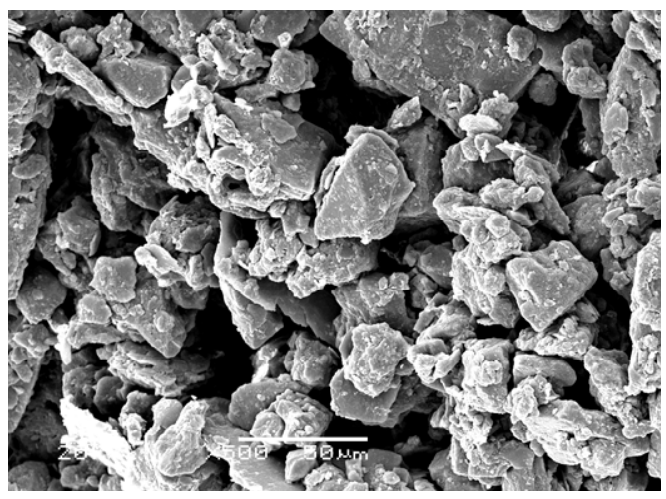

Figure 3. Yongdeng loess, $4 \mathrm{~m}$.

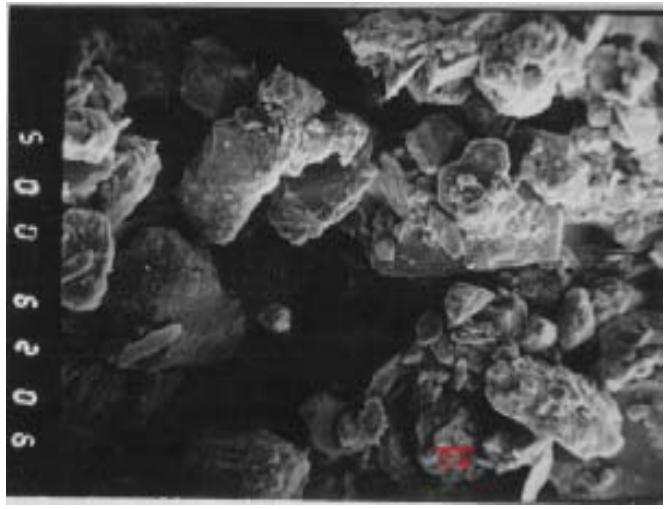

Figure 4. Dingxi loess, $5 \mathrm{~m}$.

\subsection{The Medium Seismic Subsidence Microstructure(III)}

The medium seismic subsidence microstructure is shown in Figures 5 and 6, the loess microstructure of Jingyuan and Dongxiang of Gansu province. Its characterized is by smaller and more particles, and with a moderate earthquake subsidence. Its seismic subsidence coefficient is between $3 \%-5 \%$. But, if there has long time dynamic loading on the kind of loess foundation, it could also cause some degree of permanent deformation.

\subsection{The Low Seismic Subsidence Microstructure(IV)}

The low seismic subsidence microstructure is shown in Figures $\mathbf{7}$ and 8 that loess SEM images of Linfen and Huayin of ShanXi province. The kind of loess has powder particle sizes of about 20 to $40 \mu \mathrm{m}$ or so. The microstructure characteristic is with smaller particles and pores, with relatively weak cementing between particles. These region loess, because of far from sand source, its particles is more tiny and compactness, so its seismic subsidence coefficient is only $0.4 \%-2.3 \%$.

Forming of little dry climate conditions, it has tiny particles and relative weaker cementation. When it has long time heavy rainfall, it could produce loess mud- 


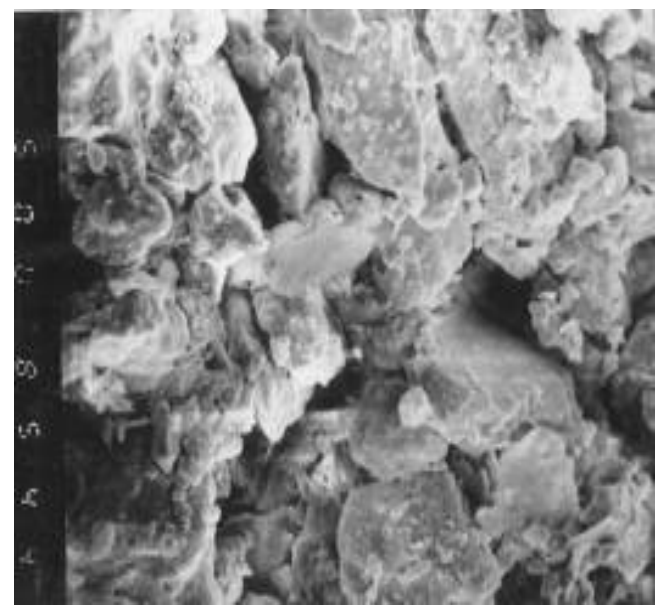

Figure 5. Loess of Jingyuan in Gansu, $5 \mathrm{~m}$.

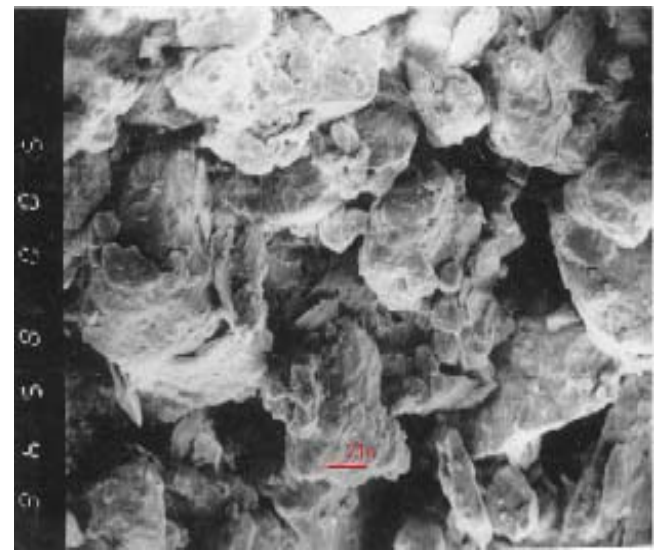

Figure 6. Dongxiang in Gansu loess $5 \mathrm{~m}$.

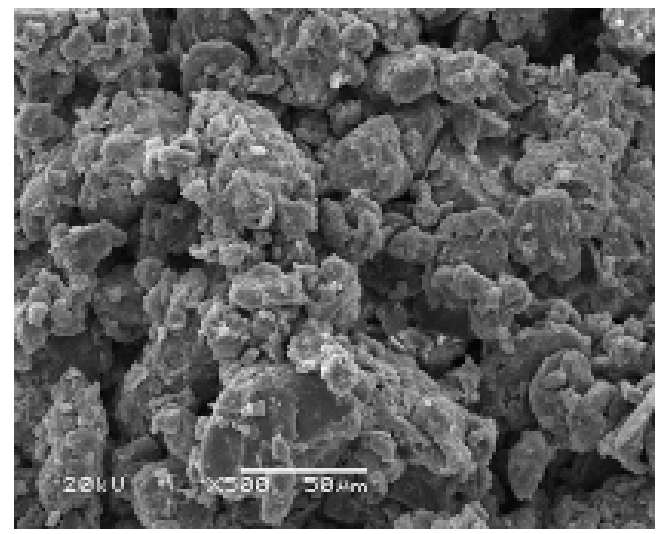

Figure 7. Linfen of Shanxi, $5 \mathrm{~m}$.

flowing, vibration landslide, and even collapsible disasters.

\section{THE RELATIONSHIP BETWEEN THE CLAY MINERALS AND ITS MICROSTRUCTURE}

Because when forming by repeat process of leaching

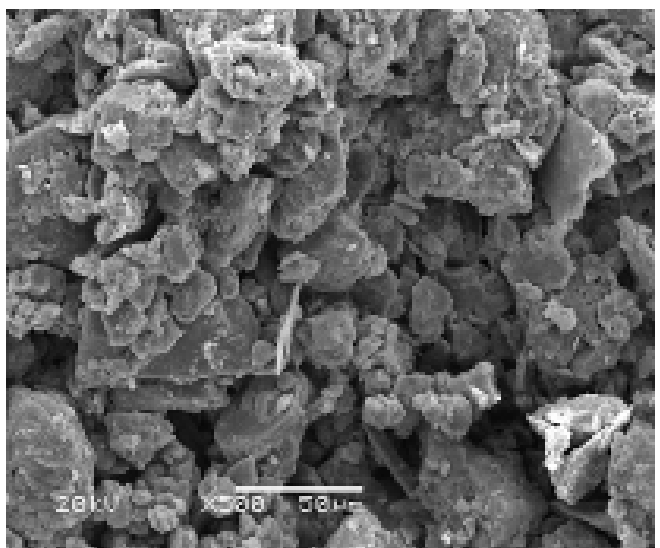

Figure 8. Huayin of Shanxi, $5 \mathrm{~m}$.

and precipitation by raining, the water flow along the easy dissolution particles pouring out into the loess pores to form clay minerals, such as quartz sand or feldspar, illite, montmorillonite and others materials. The clay minerals between loess particals can be used to analyze the relationship between loess forming conditions and the loess microstructure.

Because the course repeated during million years, the surrounding small particles of minerals have changed its chemical element radio by climate changing. The microstructure chemical composition by energy spectrum analysis can be as indicators to determine loess disaster analysis. SEM photographs taken in the energy spectrum of chemical elements used in the analysis of small area are mainly in small clay Group (small particles). The chemical element radio is below.

Under dry and cold conditions, the formed loess particles have a lot of calcification between the film and weak cementation. In the loess deposits, if the $\mathrm{Si} / \mathrm{Al}$ (Silicon/ Aluminum) ratio value is higher, then the weathering function between the loess particles will be weak. If $\mathrm{Ca} /$ $\mathrm{Mg}$ (Calcium/Magnesium) ratio is lower, it indicate as dry and cold climate. $\mathrm{K} / \mathrm{Al}$ (Potassium/Aluminum) ratio: $\mathrm{K}$ element is easily migration, but the deposition of aluminum is more stable. So this value can be used as the degree of rainfall leaching. If the ratio is larger, that shows it should be seldom raining. $\mathrm{Ca} / \mathrm{Fe}$ (Calcium/iron) ratio: small particles (clay particles) in the $\mathrm{Ca} / \mathrm{Fe}$ ratio is less than 1.0, often precedes the loess forming climate is humid and rainy.

Table 1 lists the chemical indicator ratio and clay particles microstructure types and the coefficient of settlement. The table shows that the higher chemical indicator ratio, the greater the seismic subsidence coefficient is. There are lower chemical ratios. The smaller is the deformation. According to these, indicators can divided into four types of microstructure, so as to judge kind of loading strength. 
Table 1. The chemical element Ratio and its microstructure types.

\begin{tabular}{|c|c|c|c|c|c|c|}
\hline \multirow{2}{*}{ Loss sample place } & \multirow{2}{*}{ microstructure types/ seismic subsidence } & \multirow{2}{*}{ Climatic } & \multicolumn{4}{|c|}{ Chemical Element Ratio } \\
\hline & & & $\mathrm{Si} / \mathrm{Al}$ & $\mathrm{Ca} / \mathrm{Fe}$ & $\mathrm{K} / \mathrm{Al}$ & $\mathrm{Ca} / \mathrm{Mg}$ \\
\hline Ningxia of China & $I / 4 \%-6 \%$ & $\begin{array}{l}\text { Cold, dry, near } \\
\text { sand source }\end{array}$ & 3.72 & 5.65 & 0.41 & 47.91 \\
\hline Yongdeng of China & II $/ 5 \%-8 \%$ & Cold and dry & 3.40 & 31.4 & 0.67 & 76.3 \\
\hline Jingyuan of China & $\mathrm{III} / 3 \%-5 \%$ & Cold and raining & 5.53 & 0.67 & 1.09 & 51.54 \\
\hline Huayin of China & IV $/ 0.4 \%-2.3 \%$ & Warm amd raining & 2.61 & 0.58 & 0.19 & 2.54 \\
\hline
\end{tabular}

\section{CONCLUSIONS}

1) The seismic subsidence loess of north-west China could be mainly divided into four kinds in general: strong shear deformation microstructure(I); strong compaction deformation microstructure(II); the medium seismic subsidence microstructure(III); the low seismic subsidence microstructure(IV).

2) From the loess microstructures and energy spectrum analysis, we could determine the characteristics of the loess formation conditions, and to estimate seismic subsidence in general. This is also the loess clay element radios (such as $\mathrm{Si} / \mathrm{Al}, \mathrm{Ca} / \mathrm{Fe}, \mathrm{K} / \mathrm{Al}, \mathrm{Ca} / \mathrm{Mg}$ ), and it should affect the strength of the loess as one of the basis of theoretical analysis. It could produce a new method to defense the loess environmental hazards and reinforcement.

\section{ACKNOWLEDGEMENTS}

This work was financially supported by National Natural Science foundation of China (No. 50978239) and the 2013 loess Key laboratory open fund, CEA, the fund title "Based on the microscopic mechanism of loess ground response analysis".

\section{REFERENCES}

[1] Liu, D.S. (1985) Loess and environment. Beijing Science
Press, Beijing, 1-207.

[2] Ding Z.L., Sun, J.M. and Rutter, N.W. (1999) Changes in sand of loess deposits along a North-South transect of the Chinese Loess Plateau and the implication for desert variation. Quaternary Research, 52, 56-62. doi:10.1006/qres.1999.2045

[3] Thomas, S., Imon, A.J. and Lu, H.Y. (2006) Sedimentation and diagenesis of Chinese loess implications for the preservation of continuous, high resolution climate records. Geology, 34, 849-852. doi:10.1130/G22472.1

[4] Wang, L.M. (2003) Loess dynamics. Earthquake Press, Beijing, 12-82.

[5] Deng, J., Wang, L.M. and Zhang, Z.Z. (2010) The loess microstructure characteristics and forming environment of late Quaternary Period in the Loess Plateau of China. Environmental Earth Sciences, 59, 1807-1817. doi:10.1007/s12665-009-0162-x

[6] Gao, G.-M. (1980) The loess miorostrtlcturets classification and its collapsible characteristics. Science of China, 12, 1203-1208.

[7] Deng, J., Wang, L.-M. and Zhang Z.Z. (2007) Microstructure characteristics and seismic subsidence of loess. Chinese Journal of Gentechnical Engineering, 27, 542548.

[8] Wang, L.-M., Deng, J. and Huang Y. (2007) Quantitative analysis of microstructure of loess seismic subsidence. Chinese Journal of Rock Mechanics and Engineering, 26, 3025-3033. 